\title{
TCOM \\ Climate change and public perception. Citizens' proposals for better communication and involvement
}

\section{Malgorzata Dziminska, Isabel Mendoza-Poudereux, Giuseppe Pellegrini and Jussara Rowland}

\begin{abstract}
This paper explains how a participative approach was used to collect first-hand citizens' suggestions on how to improve science communication regarding Climate Change. A public consultation involving citizens from 5 different European countries revealed various perspectives concerning their communication preferences on scientific topics. Five main themes emerged following citizens' proposals for better communication and involvement: producer of information, medium, message strategies, audiences and areas of action and engagement.
\end{abstract}

Keywords

Public engagement with science and technology; Representations of science and technology; Science and media

DOI

https://doi.org/10.22323/2.20030209

Submitted: 16th November 2020

Accepted: 30th March 2021

Published: 10th May 2021

Introduction

Climate Change is one of the greatest challenges facing humanity, «however, since the direct effects on human well-being are not always clear, it is difficult for people to conceptualise the causes of Climate Change and, conversely, the possible effects of Climate Change on their lives. This does not, however, imply that citizens are not concerned about the consequences of Climate Change» [Papoulis et al., 2015]. To investigate the main dimensions that characterise the perception of the public (beliefs, facts, values and opinions), various studies have been carried out allowing to grasp the extent of the Climate Change phenomenon in the public's imagination.

Recent Eurobarometer studies on Climate Change public opinion illustrate that almost $25 \%$ of Europeans think Climate Change is the single most serious problem facing the world [European Union, 2019]. This is an increase of 11 percentage points since the 2017 Eurobarometer. From a long-term perspective, it emerges that Climate Change is the issue that has received the highest percentage of mentions since this question was first asked, while poverty, hunger and lack of clean water are at their peak. In general, Climate Change was seen as a serious global challenge by a majority of respondents in the Nordic Member States, while respondents in 


\section{4-2020 World Newspaper Coverage of Climate Change or Global Warming}

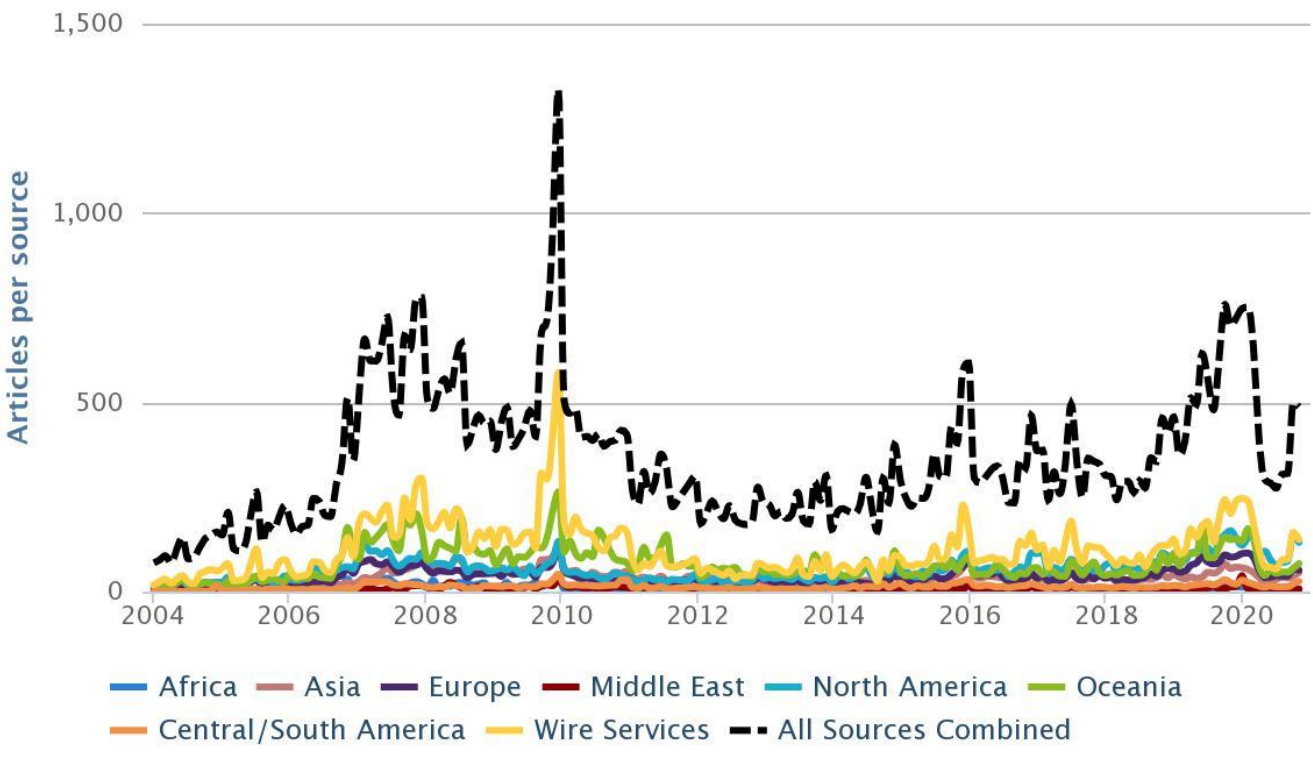

Figure 1. Newspaper media coverage of Climate Change or global warming in sixty-six sources across thirty-six countries in seven different regions around the world, from January 2004 through February 2020 [Media and Climate Change Observatory, 2020].

Eastern and Southern Member States were less likely to consider Climate Change to be a serious problem [European Union, 2019].

However, what drives public concern on Climate Change? Among the most common hypotheses by scholars is the media influence and in particular the power to propose an agenda and the priority of news. [McCombs, 2004; Dumitrescu and Mughan, 2010].

Considering some patterns used by the media, two trends become apparent. The first concerns the commitment to offer balanced information between denialist/skeptical positions and scientific facts [Boykoff and Boykoff, 2004; Painter, 2013]. The second trend is that the topic reaches peaks of interest in parallel to periods of intensive media coverage, noting 2010 as a particularly remarkable peak [Media and Climate Change Observatory, 2020], (Figure 1).

A huge number of conflicting articles and messages across the media about Climate Change have created confusion and uncertainty among the audience. This information stream, sometimes fragmentary and even chaotic, has disoriented the public [Moser, 2016; Cook and Overpeck, 2018]. Various well-established studies have shown that the public very often does not accept a communication of uncertainty. For this reason, very often both communicators and scientists are quite reluctant to talk about scientific uncertainty in fields of great public interest [Johnson and Slovic, 1995]. Climate change is a collective problem and will not be solved without public consent to facilitate policy change and/or to make the collective behavioural changes required. The role that the media might play in promoting or prohibiting these changes is of paramount importance. 
It must also be considered that scientific communication tends to be based on facts while the public tends to combine facts and values. This represents a challenge for the encounter between science and society. For this reason, institutions have tried in recent decades to intensify initiatives of public involvement. From consultations to deliberative processes, public participation initiatives have opened spaces for discussion and comparison and in some cases even the possibility to make decisions involving social partners [Dietz, 2013; van der Bles et al., 2020].

Alongside these considerations, it must be borne in mind that Climate Change requires public action. Therefore, if collective changes are to be achieved, citizens' attitudes must be paid constant attention. Furthermore, unofficial sources that contribute to spreading positions that are not based on scientific facts must be considered. The public is therefore not fully aware of the cohesion of the scientific community on the issues of Climate Change [Happer and Philo, 2015].

Another phenomenon to consider are the social media networks that are allowing non-experts to exert a significant influence on Climate Change news flow. In this way, the power of traditional media has been reduced. In a 2017 study, Newman shows that «comments on the 2013 Intergovernmental Panel on Climate Change report (IPCC) were 35\% mainstream media (e.g., CNN, The Washington Post), 23\% were new media (e.g., Buzzfeed, Huffington Post), 20\% were science news (e.g., Nature, Scientific American), 12\% were government or academic, and 9\% were advocacy sites» [Newman, 2016]. IPCC itself works through the release of its WG reports, a more media-friendly communication of WGI, «focusing on the "broad expert consensus" of climate science and quashing of uncertainty» [Pearce et al., 2018].

Scientists and scientific institutions are also an important source on the public communication front. On several occasions, at an international level, they have been questioned and challenged by proposing different ways of relating to the public. Starting from a tendential deficit model approach, scientists and experts have activated various forms of communication based on their normative references, their vision of science in society, interests and needs [Weingart and Guenther, 2016]. Scientists generally enjoy a good reputation in communicating Climate Change issues and are nevertheless regarded as credible sources even when they communicate in a full range of ways: from the closest to the deficit model to advocacy [Kotcher et al., 2017].

Public perception of environmental issues and in particular of Climate Change is relevant for its influence on political orientation. Studies on the ability of democratic and non-democratic regimes to reduce emissions to limit global warming have shown that both have failed to produce effective results [Fiorino, 2018]. For this reason, some scholars of democratic deliberation practices have suggested the importance, in some contexts, of activating forms of democratic involvement that can foster better adaptive skills agreed with citizens [Dryzek, 2002; Goodin, 2003]. However, it must be considered that citizens interpret information and skills on Climate Change in very selective and arbitrary places and often fail to adequately understand the scientific arguments to distinguish misleading and false information [Lenzi, 2019]. 
Indeed, if the public perceives little attention to environmental priorities, they will be rather skeptical of policy proposals based primarily on economic growth [Gregersen et al., 2020]. If public decision-makers do not know how to grasp these guidelines, they will hardly be able to obtain the desired consensus. "This should encourage policy makers and other societal actors to open up the public and political debate» [Drews, Antal and van den Bergh, 2018]. Public decision makers are therefore required to reformulate the political agenda to effectively connect public opinion and political action. This means, in terms of public communication, proposing new frames that can produce the desired effects by civil society and the political class [Levine and Kline, 2017].

In order to seek the views of the general public on Climate Change and three other controversial science-based topics, a public consultation procedure was developed in the EU funded CONCISE project based on the World Wide Views consultation approach [Blue and Medlock, 2014; Riedy and Herriman, 2011]. The research project was funded under the Horizon 2020-SwafS-19-2018-2019-2020 programme in the 2018 call, coordinated by the University of Valencia and involving 9 partners from five countries: Italy, Poland, Portugal, Slovakia and Spain. ${ }^{1}$

The consortium organised consultations in their respective countries with a standard format, involving one hundred volunteer citizens per country who debated in a one-day event in small groups (between 7-10 people each), with the help of a moderator and an observer. All public consultations took place between September (Italy and Poland), October (Spain) and November (Slovakia and Portugal), 2019.

The choice of public consultation as the preferred method of data collection was reasoned by the intention to 1) run multiple group discussions simultaneously; 2) create a participatory experience for the attendees and empower them by offering an opportunity to contribute to science development; 3) promote among the citizens the feeling of being a part of a national and international community. No other method could satisfy these needs; therefore, public consultation was reckoned as the most suitable one. The group discussions were applied to gain the citizens' opinions, beliefs and perceptions and benefit from the group dynamics and interactions that help uncover the reasons behind the attitudes towards a topic that may be missed through survey techniques.

The possibility of involving men and women of various ages, origins and cultural levels facilitated an exchange of views in a favourable context and allowed the free expression of the participants. In this way, a participatory context, characterised by listening and the collection of orientations, was considered. Unlike other types of consultation, oriented to the development of decisions [Fernandes-Jesus, Seixas and Carvalho, 2019; Rowe and Frewer, 2005] CONCISE's public consultation had as its central focus the collection of suggestions, criticisms and opinions to be made

\footnotetext{
${ }^{1}$ The main objective of CONCISE is to gain insights into the origins of the beliefs, perceptions and knowledge of European citizens regarding science- and technology-related issues. The project Consortium (grant agreement n. 824537) is formed by the University of Valencia (E), Observa Science in Society (IT), Trnava University (SK), FyG Consultores (E), Danmar Computers (PL), The Institute of Social Sciences of the University of Lisbon $(\mathrm{P})$, Asociación Española de Comunicación Científica (ES), University of Łódź, Faculty of Economics and Sociology, and Universitat Pompeu Fabra (E).
} 
known to the European Commission and to the public decision-makers of the countries involved. In this perspective, the methodology used favoured free exchange of opinions and constructive interaction between participants.

Allocating citizens to various discussion groups was organised to maintain group homogeneity only in terms of education background to favour group interactions. The moderator's role was essential to ensure proper focus of the discussion and maintain the good atmosphere for the conversations.

To implement the research procedure properly the five CONCISE national teams had to coordinate tightly. The common protocol for all the organisers included detailed information on which venue would be most appropriate, how to prepare the meeting rooms, how to welcome the participants and how to guide discussions, including suggestions for introductions and ice-breaking activities.

Gathering diverse and representative opinions was one of the CONCISE project prime ambitions. Therefore, to achieve the most diverse citizen sample, participants were chosen with care. To ensure this diversity, volunteers were recruited considering gender, age, educational background, ethnicity, disability, and professional careers according to statistical sociodemographic available data per country [for example, INE (https: / / www.ine.es) in Spain, ISTAT (https://www. istat.it/it/) in Italy]. General recruitment started on the July 11, 2019 and lasted until the last consultation was held in Portugal, on November 16, 2019.

The protocol and script were planned carefully to guide the meetings towards discussing science communication key points on four controversial topics. These topics were chosen among those of maximum scientific and social interest, that is, Climate Change, vaccines, genetically modified organisms, and complementary and alternative medicine. Each topic was discussed separately in a dedicated time ranging from 1 to 1,5 hour (Appendix A: the agenda). The scripts were prepared to help moderators guide the discussions to answer the three CONCISE main research objectives separately for each topic:

1. How are citizens informed? Which channels are the preferred ones to access information?

2. Reliability of sources. How do citizens rate the reliability of channels and sources?

3. What are the citizens' proposals to improve scientific communication?

This paper will examine the results of five public consultations mentioned above (held in Italy, Slovakia, Spain, Portugal and Poland) with respect to the participants' proposal for better Climate Change communication which was addressed in the third research question (Appendix B: the script). 
Public consultations were audio-recorded, integrally transcribed, and content analysed with the support of the NVivo software, a package for qualitative data analysis. Specifically, all partners shared a common grid for coding the textual corpus and for proposing cross-country comparisons. The grid, which had a tree structure, was articulated around three main sections corresponding to the three research objectives illustrated above. Each section was populated by codes emerging from the data during the coding process: in other words, the text passages deemed relevant were selected and associated with one or more pre-existing codes from the grid or new ones. Then, a coding hierarchy was developed.

Concerning the proposals for improving Climate Change communication, which is the focus of this paper, we considered five different areas. Four areas were based on the classic communication models and were: information producers, media, methods of transmission and audiences. We then conducted a thematic analysis [King and Brooks, 2018] within the corpus related to Climate Change proposals, which allowed us to identify transversal themes within these areas. This allowed us to identify on which aspects the proposals were placed and to deepen the type of recommendations suggested. The last area concerned the areas of action in which to involve civil society and engage in the co-creation process. Quotations to illustrate the main themes identified are proposed, using these general indications: nationality, gender, age range and educational level (sec. ed.: secondary level; univ.: tertiary level).

Information producers
The qualitative analysis of the data carried out with Nvivo allows us to identify the institutional and non-institutional subjects who are considered the most legitimate when informing on Climate Change issues. There are three subjects indicated as most trusted information producers on global change in all countries: scientists, institutions (e.g. governments, universities), and communicators. The analysis shows different attributions of importance between countries.

The best considered are the Scientists for Portuguese and Spanish and Institutions for Slovaks, Italians and Poles. Various figures of communicators are recognised as the third relevant component. Participants propose different aspects of the role of scientists as communicators in the context of Climate Change. In the first place, they are given the authority and competence on the subject such as the prestige and credibility necessary to obtain useful information. At the same time, in various cases, scientists who communicate on the public stage are effective and manage to make themselves understood by meeting the public's tale.
"Yes, that's what I was going to say, I think that scientists, at least for me, are still people who, precisely because of this distance from society, end up being very fascinating and I think that the fact, for example of being one day at a conference, even if it is through a webcam, having a scientist talking and speaking in a common way, that is clear, I think it is something that creates a really big impact» (Portugal, Female, 25-34, univ.).

"Antonio Turiel comes to mind, who is a CSIC $^{2}$ scientist who talks about this, and the talks he gives are on this topic» (Spain, Female, 25-34, sec. ed.).

\footnotetext{
${ }^{2}$ CSIC, the Spanish National Research Council.
} 
Institutions are asked to exercise their responsibility but not only because they are supported by citizens in the context of the rule of law, they are asked to be responsible for correctly transmitting and communicating to citizens. This request is proposed considering various levels: from the European Commission, the State and local administrations and the closer you get to the citizens there is a bigger need for an active involvement.

\begin{abstract}
"I believe that these should be institutions that are substantially involved in this type of activity. So, if we are talking [...] about the environment, then it should be the Ministry of Environment. [...] And I think that regardless of what the government is, this is why these institutions are created to inform about it, I trust that they should support it with research, right» (Poland, Male, 25-34, univ.).

«The European Community should give guidelines to ministries. [...] the standard that should provide communications and use that information on these issues within schools» (Italy, Male, 25-34, univ.).
\end{abstract}

In the mediated public sphere different actors are recognised, some of them in all 5 countries. These include experts, journalists and people who can be defined as testimonials, an increasingly important actor in recent years. Among these the figure of Greta Thunberg as an activist and spokesperson for the world of youth with her environmental struggles stands out. Her communication skills and her media influence on Climate Change have produced an international mobilisation. Environmental associations are also seen as important communicative actors, especially for their ability to involve citizens at the local level.

"In Florence it happened that after this thing about Greta [...] they made a demonstration against plastic, [...] we want a better environment as she wants, because we fight with her» (Italy, Female, 18-24, sec. ed.).

"Well, only non-governmental organisations that just / some meetings, some picnics related to it, what is now happening among young people with this climate strike, make people very aware, for example kids make their parents aware» (Poland, Female, 55-64, univ.).

"A young Swedish woman who has been popular only recently but her campaign started two years ago. She sat in front of the Swedish parliament for two years before» (Slovakia, Male, 45-54, sec. ed.)

A particularly important element concerns the commitment that citizens can have in public communication on Climate Change. Also, in this case, many participants in the consultation underlined the key role of the new generations, in part well represented by the commitment of young testimonials.

"Some young people are more aware than we are. As they tell us we are destroying their planet. It has a strong emotional appeal. It embarrasses us. It is very important, I think... Maybe it is sometimes even more important than scientific argumentation» (Poland, Female, 35-44, univ.). 
The analysis of the conversations highlighted the relevance of the media as an effective interface for engaging the public and informing on the topic of Climate Change [Weingart and Guenther, 2016]. In the first instance, the means deemed most suitable for communicating are traditional media and the educational system understood as school institutions and training centres.

Italians, Spanish and Portuguese believe that TV, newspapers and radio are the most effective means of raising awareness and interest in the public on global warming and the environment. These media allow for a more in-depth knowledge of the issues of Climate Change and also allow a more reasoned sharing and also discussions between different subjects. Participants say that TV is the best medium that can have an impact on those who don't normally engage with science communication, so they suggest more scientific content, on primetime.

"Each television channel should have a specific time to talk about these topics. That is the only chance that exists! It's not only talking about the topic on a newscast, superficially, and then stop!... I don't know... half an hour, specifically to talk about these topics on television. Just to talk about these topics, which is very important. If this is not television, it is not worth it» (Portugal, Male, 55-64, sec. ed.).

Alongside traditional media, the importance of school education is recognised on several occasions, particularly in Slovakia, Spain and Poland. The educational system is pointed as the strongest medium for communicating scientific content. In kindergartens, in schools, especially during geography and biology classes. Critical thinking and the use of scientific methods should be more emphasised in the educational programs. Teachers need more professional development on how to deliver the content using these methods.

"This is the only way, in my opinion, i.e. through school education, additional projects, I do not know, teachers should receive good money, e.g. to run such projects, additional classes in schools» (Poland, Female, 25-34, univ.).

"We need to do more in schools of all levels. We need to create people aware of the fact that if one day they become the Trump of the day, they set fire to the Amazon rainforest» (Italy, Male, 45-54, sec. ed.).

"I think that education is very important, but first the family and only then the school has children to lead the issue, children repeat what they see in parents, it is a connection with education, which brings a better result» (Slovakia, Female, 18-24, sec. ed.).

"It would be nice if there was a subject in education where young children could learn how to live ecologically» (Slovakia, Female, 18-24, sec. ed.).

Social media are recognised as easy to use and immediate means of reaching the general public. At the same time, there is a need to verify the sources and messages to make sure you get the correct information.

"I think if we had people like we used to have in the new... [... If they went to the social networks to present. . We have to adapt to the circumstances; this would work better. We used to have people in that field and everybody understood what the person said» (Portugal, Male, 45-54, sec. ed.). 
«I don't read a tweet from the minister, but I realise it's my limit. It's an official tweet. So that's fine, okay. Let's say there must be an official position» (Italy, Female, 35-44, univ).

"So again, I use Facebook, Instagram and then various pages so I would look for the information basically through some of the groups I follow» (Slovakia, Female, 25-34, univ.).

Methods of transmission

Format and language are mentioned on more occasions than content in 4 of the countries and on equal terms in the one remaining. The citizens across the five countries highlight that the content of messages on Climate Change must, most of all, be factual and truthful. The perception that the content is based on facts is supported when the message is accompanied by sources that allow them to verify the news.

"And then, sometimes, it might help if they put a reference because if they are commenting on a news story and they don't say where that data comes from, well, you, you can believe it or not, but you can't verify it» (Spain, Male, 45-54, univ.).

The citizens advocate to illustrate the messages with examples of actual behaviours and actions, both environmentally friendly and detrimental ones. The reported activities should be commented on with information on the consequences they bring and accompanied with an encouragement for an individual's agency.

\begin{abstract}
"I think that all the news related to the issue of Climate Change should have at least three parts. The event, the news itself, the consequence in people's lives, in my life. And what I can do to contribute positively». (Portugal, Male, 18-24, sec. ed.).

«I think the latest information film was just released, propagated by Greta Thunberg and I think it is a masterpiece of short propaganda films [... ] she talks to a scientist who tells about what is happening and, in the end, she says what you can do. Three things: either first of all, share information, this video, secondly - make your friends aware, thirdly - if you can, apply it yourself. [... ], I think that these types of videos are..., I found it perfect» (Poland, Female, 35-44, univ.).
\end{abstract}

The citizens suggest that the messages should present the problems and solutions by applying various perspectives: the macro-level view — of a planet; the meso-level - of a country; the local level — of a local community and most of all the micro-level — of an individual.

The macro-level perspective contributes to raising awareness on the scale of a problem for the whole world and it makes people realise how urgent this problem is for the planet.

"What I would like most is to find such big facts, [...]. Not something that the percentage of greenhouse gases increases by some per mile or a small percentage in the atmosphere, but for example, [...] if we convert it into mass or volume, then here we are talking about unimaginable values, about tens or hundreds of thousands of tons of greenhouse gases per second, yes, with the greatest temperature increase in millions of years, with billions of people who will not have a home. I think these are facts that will affect people more and more effectively» (Poland, Male, 18-24, sec. ed.). 
The meso-level perspective should focus on informing the public on what the governments and national bodies are doing to prevent Climate Change and introduce measures that support environmentally friendly solutions. Such messages should be prepared by independent bodies so that the message is not politically biased.

"Apart from seeing a little [...], what movements are they doing, what laws are there right now that are oriented towards avoiding this change, what is in force right now and all this type of information, that I do not see either» (Spain, Female, 25-34, univ.).

"What would be needed is more transparency, $[\ldots]$ and, above all, more independent audits, that is, the audits should be done by people who do not depend on any type of that political power, the sitting executive power» (Spain, Male, 35-44, univ.).

Citizens advocated also that the national bodies like governments should make better use of their power to run very impactful communication strategies on scientific topics. They could for example oblige the TV stations to devote more prime time to presenting socially important issues.

«I think, for example, it could be ... for example, be an obligation of those in the government, forcing that there be [information on the topic] on public channels at so-called prime time. Like Minuto Verde, [...] but there should be time to disseminate information on the day's issues [...] With this importance. I think there should be ...» (Portugal, Female, 55-64, univ.).

The local level perspective should focus on presenting the problems in the nearest vicinity, so that people can pay more attention to what consequences Climate Change and their actions carry for their neighbourhood.

\footnotetext{
"Think there must also be more... the researchers... communication must also involve a practical part, working with people... identifying in the case of Climate Change a population in a coastal area, which has different problems than a population in the interior. Ready. Adapt communication and work with these populations to their realities» (Portugal, Female, 27, univ.).

"As I said before, the municipalities. Parish councils should have a more active role in this and more. They should inform and show attitudes that one should have. [...] Give examples and show films. People have to see to believe» (Portugal, Female, 45-54, univ.).
}

Finally, the micro-level view should be represented by messages relevant for an individual, problems and solutions should be shown through the eyes of a citizen, for example how an individual can save money by saving energy or how much he can contribute to decreasing smog if he uses a bike.

«(...) that they inform us more about what each citizen can do to improve» (Spain, Female, 65 or more, no formal education).

The citizens advocated the use of multiple formats as suitable for communicating the topic of Climate Change. What was repeated across all countries was that no 
matter what format it is (advertising, educational and social campaigns, scientific debates or programs on TV, press coverage, radio programs, or news on digital media) the following key elements must be paid most attention to: good communicators, wider use of creativity to hook the attention and interest of the audience and better application of visual techniques.

Good communicators can be recruited from scientists, journalists, celebrities, bloggers. The key is to find a person who can win the interest of the audience and pass the message with an impact. It is very well received when scientists engage in direct communication with citizens.

"Piero Angela [the most famous Italian science journalists] explained things like this, that is, he was concise, he said the things that everyone could understand, I was a kid and I understood perfectly and yet he spoke in a way with enough scientific terms so ... he was neutral, he did not give you anxiety» (Italy, Male, 25-34, sec. ed.).

"There is such a channel produced by the Copernicus Center [Centrum Nauki Kopernik] and there [...] is a scientist there, every week or so, he discusses the next issue of Nature. Well, it's fantastic, it's fantastic to listen to it» (Poland, Female, 35-44, univ.).

"I have such a specific experience, the first one from school when the professor released a film with Leo DiCaprio within the subject of environmental management» (Slovakia, Male, 25-34, univ.).

The citizens advocated the wider use of creativity to use existing formats and look for new ones, less obvious ones, for example, organise art exhibitions where sculptures are made of plastic or organise actions where citizens can create their eco-bags. The use of various formats allows us to reach more types of public, managing to intrigue and make them more aware.

"I think that such information spreads well at large festivals of various types, for example at Woodstock. Greenpeace, look, they were so active at Woodstock, I learned there about the problems with the Baltic Sea just at Woodstock, yes. There were half a million people there, and everyone was hooked somewhere, they just got leaflets, invitations to meetings with specialists in the fields of biology, meteorology, chemistry and so on» (Poland, Female, 25-34, univ.).

A lot of citizens indicated a need for better use of the visual methods of presenting facts, for example engaging videos, infographics, nicely prepared visualisations of data and charts. Visual communication strategies are very effective in bringing the public closer to issues of environmental interest and in particular to critical situations caused by global warming.

"I think a lot, as you said, about simplicity, that is, about how information arrives so I think that the visual impact, for example, the Amazon forest burns, put on the news». (Italy, Male, 45-54, univ.)

"For those willing to read, but also with pictures. There must always be this connection, I'm talking about the visual side of a message». (Poland, Female, 45-54, univ.). 
The message should also engage people emotionally. Passionate discussions, catchy slogans or entertaining language are seen as supportive factors in getting the message across. The ability to excite with icons representative of the evident effects of Climate Change makes it possible to quickly approach a large audience.

\author{
"Maybe making a more emotional impact on people is what initiates change [...]» \\ (Spain, Male, 55-64, univ.). \\ "Emotions, in my opinion, only emotions. [...] It should be simple words and \\ emotions» (Poland, Female, 35-44, univ.). \\ "And the other thing that I also think is missing is the fact that things should be \\ transmitted in an exciting and fun, passionate way" (Portugal, Female, 35-44, \\ univ.). \\ "I am quite influenced by those videos where they show specific things that are \\ happening to the planet, it affects me quite a lot and they actually aroused a new \\ attitude in me» (Slovakia, Female, 18-24, sec. ed.).
}

\title{
Audiences
}

Citizens' proposals took into account the importance of making science more accessible for everyone and the need to focus on the specific needs of different social groups. Participants across all countries expect most of all simple, understandable language, operating on facts, presenting the content objectively. Scientists are expected to adjust their language so that their message is understandable for a layman.
"In my opinion, in general, publications should be written in everyday language, so that it reaches everyone» (Poland, Female, 25-34, univ.).
"The information obviously has to have a scientific basis, but it has to have a language that the person can read and is interested in. Because otherwise, if it's very scientific, people read three lines, this is not for me that I don't understand». (Portugal, Female, 55-64, univ.).

Citizens' concerns also addressed the needs of those who have more difficulty understanding scientific information, or those that are hard to reach for several reasons. Participants often associated this need with elderly citizens:
"So, I would like more direct news. Less biased and simpler as possible, within everyone's reach. Like my father, a person of seventy-eight, but who knows about fine dust, who asks me "what is this fine dust, how can I remove it?". So simple language, which is understandable even to those who are eighty" (Italy, Male, 45-55, sec. ed.).
"That's the question. If there was someone who could simplify the messages that are transmitted, it would be much easier, maybe, so my grandparents could understand what is there and maybe become aware of what is probably important. Now, I'm going to read an article, I'll give it on to my grandmother, for example, she'll probably lose interest in the first sentence. It's a little bit complicated, so if there was a television... » (Portugal, Female , 18-24, secondary).

The same attention is also given to the younger generation. Young people have different interest and ways of relating to science communication, and it is important to develop specific strategies to be able to reach them: 
«Scientists communicate with us, we have to tell them how. I guess with colloquial language, but suited to different generations, because young people are different. They will react to something different than people our age» (Poland, Female, 45-54, univ.).

Children and young people were, in fact, often referred to as an audience target in all countries, but especially in Italy and Poland. Children were considered a priority group for different reasons. On one hand, they are more open to learning and easily accessible through the school system. In this case, they are often considered as "adults of tomorrow", the attention being more on their future perceptions and actions on Climate Change. From this perspective, it seems that the implicit message of adults is the difficulty of following the pace of scientific information from various media and in particular digital media, highlighting a gap that is difficult to fill.

"Start communicating science well to children because they are the adults of tomorrow. I have this memory of Rio in '92 I was in school and my teacher was passionate about it and in any case, she passed this information on to me» (Italy, Female, 35-44, univ.).

"I believe that is the way. It is starting with the kindergarten, with the little ones... to educate citizens that are more aware so that we can better choose who represents us" (Portugal, Female, 55-64, univ.).

On the other hand, citizens also considered the importance of the role children and young people can have already on Climate Change. The example of virtuous behaviour experienced by children can be contagious and stimulating. They are an important medium to reach adults since children can take the information home and stimulate climate-friendly behaviours among family adults. But they can also contribute directly, setting up initiatives related to Climate Change.

"For me, one of the ways in which [information on CC] gets to my home is through schools. My daughter brings information home. And, perhaps, some of you, children, grandchildren, nephews... I think it was important that whoever studies this, in academic terms, should give mini conferences in schools! Because when we started to sort the garbage at home, a lot of that stimulus came from the children!» (Portugal, Female, 45-54, univ.).

Lastly, citizens also consider that in order for science communication on Climate Change to be effective, it is important to take into consideration differences between communities. The rationale here, is that not only their needs are different, but people care more about issues that affect them directly:

"The public does not care what is done there in Kraków or Gdynia. It is important what is done in my neighbourhood. If nothing is done here, then [...]. There are few people in society who have such a broad perspective that covers the whole, all of our affairs, the effects of our actions like this... No, because the majority of society is interested in me, themselves, their family and local environment» (Poland, Female, 65 or more, univ.).

Neglecting the differences on how the different generations and different communities are impacted by the risk posed by Climate Change and how they relate to scientific information on the subject, will lead, according to citizens, to less effective science communication and lower engagement levels. 
Citizens

engagement and

co-creation
The analysis of the data made it possible to identify two other important dimensions of science communication noted by citizens in the discussion related to citizens' involvement: public engagement and co-creation. For these two dimensions the participants formulated two types of proposals:

- suggestions for public engagement: proposal on fostering intentional and meaningful interactions between scientists and the public to provide opportunities for mutual learning, to enhance civic engagement skills and empowerment,

- suggestions for co-creation and bottom-up influencing: recommendations on how to encourage active involvement of the public to bring in additional knowledge and creativity, to build partnerships and trust, to foster legitimacy and acceptance and influence governance and/or business practices.

Most common suggestions are related to public engagement demands. Citizens highlight the need to establish direct channels of communication between the scientists working directly on the topics and the public that may be impacted by their findings. These channels include public consultation meetings like the one they were participating in.

\footnotetext{
«... maybe, projects where, like today, where there is participation, where consortia or projects are created where companies, research centres, consumer associations participate, and they meet to talk about these things and make commitments... » (Spain, male, 55-64, univ).

«So, for example, more initiatives. In this case it is a public consultation, but doing this type of ... sometimes there is also the issue of people not participating, there is always the other side of the coin that is people not participating, but creating these ... these lectures, these debates. Sometimes maybe it's not just a lecture with a person talking. It's the debate. "Why don't you think it is?" "What do you think it is?" And there is a person there who knows how to deal with the situation, so bring matters to the public, so that the public can give their opinions on the subject, see what they know, what they don't know, interact... (Portugal, female, 25-34, univ.).
}

The second type of suggestion is related to the notion of co-creation, i.e. the ways the public might participate in Climate Change mitigation, by influencing other citizens or even shaping the focus of Climate Change research.

\footnotetext{
"That is why we ourselves have to teach these people, both in supermarkets and when you go to the market, to businessmen, to say "that's it, we don't want it, we're not going to spend it» (Spain, female, 55-64, primary school).

"But when I go and when I see garbage, I don't pass by and pretend it's not there, we clean it up first, we bring it home, I throw it into my container and when there's a school trip, Hania is told, "but you're not going, because by the time you clean up, there won't be any sausage". And it's not only that she cleans up, she chases other kids to clean up too» (Poland, female, 25-34, sec. ed.).
} 
Discussion and conclusions
There is great value in the information gained from the citizens on how to improve science communication with relation to Climate Change. The process of public consultation forms an example of the "dialogue" approach, in which the interactions between science representatives and citizens are mutually informing [Davies et al., 2009]. Engaging citizens to inform on how to improve science communication concerning Climate Change offered an opportunity to empathise and gain insights into the needs and expectations of society on its preferences to ways of being informed about scientific issues.

As discussed in the introduction, values, opinions and beliefs have a strong influence among the public. Also, during the public consultations, and in particular in the definition of effective communication proposals, the reference to these aspects was highlighted.

Analysis of the citizens' suggestions in the five countries revealed strong similarities in ideas on how to improve Climate Change related science communication. These ideas involve reliance on truthful and verified information, application of a variety of formats to meet diverse perception tastes of the audience and the use of language that is understandable and tailored to different groups, including children, youth, adults and elderly, their education level, profession or place of living. The presentation of scientific facts should involve multiple perspectives: individual, local, national and global, so that the information receiver can see the topic of Climate Change and its consequences with relation to his own life, the neighbourhood he lives in, the country, and the world. Of course, certain proposals represent wishes that are not easily achievable since often the institutions do not dialogue with each other or have very different perspectives.

The analysis of the data revealed some differences in attitude between generations. Young people from the countries involved in the public consultation are generally very sensitive to the issue and active in seeking information and ways of involvement. The greatest differences between generations and cultural level concern the use of media. In general, in all countries, adults suggest a priority use of traditional media while young people prefer social media and influencers as witnesses of the commitment to mitigate Climate Change.

In the case of Slovakia there are no significant differences between generations and cultural levels in the proposals. Information is requested on behaviour for sustainability and public moments of in-depth analysis with and by experts.

The main difference between countries regards who should communicate scientific information. The position of the Spanish and Portuguese participants on information producers is very much oriented towards considering scientists and experts as those who are the most authoritative in speaking to the public about issues concerning the causes and effects of Climate Change. In this perspective, they rely on scientific truth as an element of guarantee proposed by the world of scientific research understood as an independent and widely reliable institution. A Mertonian vision of the ethos of the scientist dedicated to the public good is recognised in this position [Brüggemann, Lörcher and Walter, 2020]. As public actors, scientists and researchers can play the role of communicators and become effective witnesses to be able to talk about one of the most felt issues by the public and the undesirable consequences of Climate Change. On the other hand, Italian, 
Slovakian and Polish participants highlighted the role of institutions and communicators on science communication. These two positions recognise on the one hand the need for a public guarantee role due to the trust in institutions as responsible and representative of the public good. On the other hand, the role of communicators in the media arena is considered to be more neutral and less influenced by political orientations, such as to be able to offer correct, comprehensive and balanced information. What was highlighted across the nations was that the communicating bodies should be free from political, financial and ideological influences so that the topic of Climate Change is presented without such bias.

The most often referenced media for communicating Climate Change were: traditional media, especially TV, educational system and digital media, with different attributions between the countries. Traditional media was more often referred to by Italian, Portuguese and Spanish participants, digital media by the Slovakian and a mix of both by the Polish participants. Television, understood as a popular and effective medium for speaking to the population, is seen as an effective and easily accessible medium, especially for adults and the elderly. In citizens' opinions, TV needs to devote more prime time to broadcasting scientific news, digital media need a system of news verification, and the school systems need to play a greater role in teaching scientific methods, critical thinking and raising awareness of the importance of this topic (for example by the wider promotion of climate-friendly behaviours). Educational institutions are considered an important means of transmitting knowledge on environmental issues and in particular for Climate Change for their ability to influence the new generations.

An important dimension of science communication highlighted by citizens' proposals was the need for an active involvement between scientists and the science publics. Citizens' proposals included suggestions related to the need to develop science communication initiatives that foster citizens' direct involvement. This has a double meaning. On one hand, citizens asked for science communication initiatives that foster public engagement and create opportunities for citizens to get involved with scientists and to participate in scientific debates. These include debates, consultations and other participatory formats. On the other hand, they want science communication to recognise citizens as active agents in Climate Change mitigation processes. This means that they can have an important and active role in science communication that should be not only acknowledged but also empowered through multiple initiatives.

Consultation processes are based on the principle that those affected by an issue should be included in decision-making processes. This is particularly relevant when addressing a topic with the societal relevance of Climate Change. Science communication has until recently, neglected the perspective of the public. With this study, we help to show how beneficial for the research process an inclusive approach and collaboration between science and society can be and thus bring valuable results encompassing the views of the public, the key stakeholders of the Climate Change challenge. 


\begin{tabular}{|c|c|}
\hline Welcome phase & $\begin{array}{l}\text { Registration }(1 \mathrm{~h}) \\
\text { Welcome }(0,5 \mathrm{~h})\end{array}$ \\
\hline Consultation & $\begin{array}{l}\text { Discussions - round } 1 \text { Climate Change }(1-1,5 \mathrm{~h}) \\
\text { Coffee break (15 min.) } \\
\text { Discussions - round } 2 \text { Vaccines }(1-1,5 \mathrm{~h}) \\
\text { Lunch }(0,5-1 \mathrm{~h}) \\
\text { Discussions - round } 3 \text { Gmos }(1-1,5 \mathrm{~h}) \\
\text { Coffee break (15 min.) } \\
\text { Discussions - round } 4 \text { Complementary Alternative Medicine }(1-1,5 \mathrm{~h})\end{array}$ \\
\hline Final phase & $\begin{array}{l}\text { Final evaluations }(0,5 \mathrm{~h}) \\
\text { Public Consultation Closing }(0,5 \mathrm{~h})\end{array}$ \\
\hline
\end{tabular}

Appendix B.

\section{Climate change public consultation script}

\begin{tabular}{|c|c|}
\hline \multicolumn{2}{|r|}{ Objective 1: How citizens are informed } \\
\hline $\begin{array}{l}\text { Approx. } 15 \\
\text { minutes }\end{array}$ & $\begin{array}{l}\text { Do you remember any news about climate change? What was it about? } \\
\text { [ If the channel is not mentioned] } \\
\text { Do you remember in what situation you have heard / read / seen it? (Pos- } \\
\text { sible answers; in the TV news, talking to friends / relatives / colleagues, I } \\
\text { received it on WhatsApp, I read it in the newspaper, I read it on twitter ...) } \\
\text { Is climate change a topic on which you deliberately search for informa- } \\
\text { tion? Why/why not? } \\
\text { [ If participants do not mention what is done with the information they } \\
\text { receive] } \\
\text { If you receive information about climate change that you consider inter- } \\
\text { esting, what do you do? (Possible answers; Share it, send it, talk about } \\
\text { it...) } \\
\text { [ If gender dimension is not mentioned] } \\
\text { Can you remember if someone appeared in this news? Was it a man or a } \\
\text { woman? }\end{array}$ \\
\hline \multicolumn{2}{|r|}{ Objective 2. Reliability of sources } \\
\hline $\begin{array}{l}\text { Approx. } 15 \\
\text { minutes }\end{array}$ & $\begin{array}{l}\text { If you would like to know some specific information about climate } \\
\text { change, where would you look? Who would you ask? } \\
\text { [ If participants do not mention where they look for the information] } \\
\text { When you receive information about climate change, do you notice where } \\
\text { it comes from? How do you decide if a source is reliable or not? } \\
\text { Have you ever search on Internet information on climate change? What } \\
\text { webs/sources? Is there any favourite? If so, why? } \\
\text { [ If gender dimension is not mentioned] } \\
\text { Can you think of someone who is a reference for climate change? Why } \\
\text { her/him? }\end{array}$ \\
\hline \multicolumn{2}{|r|}{ Objective 3: Proposals to improve scientific communication } \\
\hline $\begin{array}{l}\text { Approx. } 15 \\
\text { minutes }\end{array}$ & $\begin{array}{l}\text { What you could change to make information about climate m } \\
\text { ing/complete/reliable? } \\
\text { How would you like the information on this topic to be? }\end{array}$ \\
\hline \multicolumn{2}{|r|}{ End of discussion } \\
\hline $15 \mathrm{mir}$ & 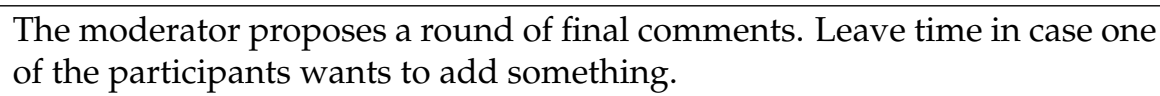 \\
\hline
\end{tabular}


Blue, G. and Medlock, J. (2014). ‘Public Engagement with Climate Change as Scientific Citizenship: A Case Study of World Wide Views on Global Warming'. Science as Culture 23 (4), pp. 560-579. https://doi.org/10.1080/09505431.2014.917620.

Boykoff, M. T. and Boykoff, J. M. (2004). 'Balance as bias: global warming and the US prestige press'. Global Environmental Change 14 (2), pp. 125-136. https://doi.org/10.1016/j.gloenvcha.2003.10.001.

Boykoff, M., Katzung, J. and Nacu-Schmidt, A. (2019). 'Media and Climate Change Observatory Monthly Summary: The Earth is facing a climate change deadline' (26). https://doi.org/10.25810/N3QX-9X31.

Brüggemann, M., Lörcher, I. and Walter, S. (2020). 'Post-normal science communication: exploring the blurring boundaries of science and journalism'. JCOM 19 (03), A02. https: //doi .org/10.22323/2.19030202.

Carvalho, A., Wessel, M. van and Maeseele, P. (2016). 'Communication Practices and Political Engagement with Climate Change: A Research Agenda'. Environmental Communication 11 (1), pp. 122-135. https://doi.org/10.1080/17524032.2016.1241815.

Cook, B. R. and Overpeck, J. T. (2018). 'Relationship-building between climate scientists and publics as an alternative to information transfer'. Wiley Interdisciplinary Reviews: Climate Change 10 (2). https://doi.org/10.1002/wcc.570.

Davies, S., McCallie, E., Simonsson, E., Lehr, J. L. and Duensing, S. (2009). 'Discussing dialogue: perspectives on the value of science dialogue events that do not inform policy'. Public Understanding of Science 18 (3), pp. 338-353. https://doi.org/10.1177/0963662507079760.

Dietz, T. (2013). 'Bringing values and deliberation to science communication'. Proceedings of the National Academy of Sciences 110 (S3), pp. 14081-14087. https://doi.org/10.1073/pnas.1212740110.

Drews, S., Antal, M. and van den Bergh, J. C. J. M. (2018). 'Challenges in Assessing Public Opinion on Economic Growth Versus Environment: Considering European and US Data'. Ecological Economics 146, pp. 265-272. https://doi.org/10.1016/j.ecolecon.2017.11.006.

Dryzek, J. S. (2002). Deliberative democracy and beyond: liberals, critics, contestations. Oxford, U.K.: Oxford University Press. https://doi.org/10.1093/019925043x.001.0001.

Dumitrescu, D. and Mughan, A. (2010). 'Mass Media and Democratic Politics. State and Society in Global Perspective'. In: Handbook of Politics. Ed. by K. T. Leicht and J. C. Jenkins. New York, U.S.A.: Springer, pp. 477-491. https://doi.org/10.1007/978-0-387-68930-2_26.

European Union (2019). Special Eurobarometer 490 - Climate Change. Bruxelles, Belgium. URL: https://www . buildup.eu/en/practices/publications/specia l-eurobarometer-490-climate-change.

Fernandes-Jesus, M., Seixas, E. C. and Carvalho, A. (2019). 'Para além dos obstáculos: experiências de consultas públicas e a possibilidade de ética e relevância na participação'. Comunicação e Sociedade 36, pp. 57-80. https://doi.org/10.17231/comsoc.36(2019). 2345.

Fiorino, D. J. (2018). Can Democracy Handle Climate Change? Cambridge, U.K.: Polity Press.

Goodin, R. E. (2003). Reflective Democracy. https://doi.org/10.1093/0199256179.001.0001. 
Gregersen, T., Doran, R., Böhm, G., Tvinnereim, E. and Poortinga, W. (2020). 'Political Orientation Moderates the Relationship Between Climate Change Beliefs and Worry About Climate Change'. Frontiers in Psychology 11. https://doi.org/10.3389/fpsyg.2020.01573.

Happer, C. and Philo, G. (2015). 'New approaches to understanding the role of the news media in the formation of public attitudes and behaviours on climate change'. European Journal of Communication 31 (2), pp. 136-151. https://doi.org/10.1177/0267323115612213.

Johnson, B. B. and Slovic, P. (1995). 'Presenting uncertainty in health risk assessment: initial studies of its effects on risk perception and trust'. Risk Analysis 15 (4), pp. 485-494. https://doi.org/10.1111/j.1539-6924.1995.tb00341.x.

King, N. and Brooks, J. (2018). 'Thematic Analysis in Organisational Research'. In: The SAGE Handbook of Qualitative Business and Management Research Methods: Methods and Challenges. SAGE Publications Ltd, pp. 219-236. https://doi.org/10.4135/9781526430236.n14.

Kotcher, J. E., Myers, T. A., Vraga, E. K., Stenhouse, N. and Maibach, E. W. (2017). 'Does engagement in advocacy hurt the credibility of scientists? Results from a randomized national survey experiment'. Environmental Communication 11 (3), pp. 415-429. https://doi.org/10.1080/17524032.2016.1275736.

Lenzi, D. (2019). 'Deliberating about Climate Change: The Case for 'Thinking and Nudging". Moral Philosophy and Politics 6 (2), pp. 313-336. https://doi .org/10.1515/mopp-2018-0034.

Levine, A. S. and Kline, R. (2017). 'A new approach for evaluating climate change communication'. Climatic Change 142 (1-2), pp. 301-309. https://doi.org/10.1007/s10584-017-1952-x.

McCombs, M. E. (2004). Setting the agenda: the mass media and public opinion. Cambridge, U.K.: Polity.

Media and Climate Change Observatory (2020). 2004-2020 Newspaper Coverage of Climate Change or Global Warming. University of Colorado Boulder. URL: http: //mecco. colorado.edu.

Moser, S. C. (2016). 'Reflections on climate change communication research and practice in the second decade of the 21st century: what more is there to say?' Wiley Interdisciplinary Reviews: Climate Change 7 (3), pp. 345-369. https://doi.org/10.1002/wcc. 403.

Muradova, L., Walker, H. and Colli, F. (2020). 'Climate change communication and public engagement in interpersonal deliberative settings: evidence from the Irish citizens' assembly'. Climate Policy 20 (10), pp. 1322-1335. https://doi.org/10.1080/14693062.2020.1777928.

Newman, T. P. (2016). 'Tracking the release of IPCC AR5 on Twitter: Users, comments, and sources following the release of the Working Group I Summary for Policymakers'. Public Understanding of Science 26 (7), pp. 815-825. https://doi.org/10.1177/0963662516628477.

Painter, J. (2013). Climate change in the media: reporting risk and uncertainty. London, U.K.: IB Tauris \& Co Ltd. and the Reuters Institute for the Study of Journalism. URL: https://ora.ox.ac.uk/objects/uuid:682a3373-8508-4e748cfc-a96e5d6d3d1a..

Papoulis, D., Kaika, D., Bampatsou, C. and Zervas, E. (2015). 'Public Perception of Climate Change in a Period of Economic Crisis'. Climate 3 (3), pp. 715-726. https://doi.org/10.3390/cli3030715. 
Pearce, W., Niederer, S., Özkula, S. M. and Querubín, N. S. (2018). 'The social media life of climate change: Platforms, publics, and future imaginaries'. Wiley Interdisciplinary Reviews: Climate Change 10 (2), e569. https://doi.org/10.1002/wcc. 569.

Riedy, C. and Herriman, J. (2011). 'Deliberative Mini-Publics and the Global Deliberative System: Insights from an Evaluation of World Wide Views on Global Warming in Australia'. Journal of Multidisciplinary International Studies 8 (3), pp. 1-29. URL: http://hdl . handle . net/10453/18959.

Rowe, G. and Frewer, L. J. (2005). 'A Typology of Public Engagement Mechanisms'. Science, Technology \& Human Values 30 (2), pp. 251-290. https://doi.org/10.1177/0162243904271724.

van der Bles, A. M., van der Linden, S., Freeman, A. L. J. and Spiegelhalter, D. J. (2020). 'The effects of communicating uncertainty on public trust in facts and numbers'. Proceedings of the National Academy of Sciences 117 (14), pp. 7672-7683. https://doi.org/10.1073/pnas.1913678117.

Weingart, P. and Guenther, L. (2016). 'Science communication and the issue of trust'. JCOM 15 (05), C01. https: //doi .org/10.22323/2.15050301.

Malgorzata Dziminska, PhD, Associate Professor at the University of Lodz, Poland. She teaches communication, critical thinking, design thinking, project management and research strategies. Her research interest concentrate on higher education management, data use for educational improvement and science communication. E-mail: malgorzata.dziminska@uni.lodz.pl.

Isabel Mendoza-Poudereux holds a PhD in Biotechnology (2013) and a Master's Degree in Creation and Management of Innovative Companies (2015). She currently compiles her work with the ScienceFlows research group at the University of Valencia with her work as communications officer for The Global Plant Council. E-mail: isabel.mendoza@uv.es.

Giuseppe Pellegrini, PhD, teaches Innovation, Technology and Society at the University of Trento. His main research interests are related to the study of science, technology and society issues. In this area of investigation, a specific attention he devoted to public engagement and public communication. He is the president of Observa Science in Society. E-mail: giuseppe.pellegrini@unitn.it.

Jussara Rowland, a sociologist and a researcher at Instituto de Ciências Sociais da Universidade de Lisboa. She explores children's and young people's roles, science communication, and participatory methodologies.

E-mail: jussara.rowland@ics.ulisboa.pt.

How to cite

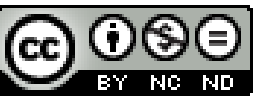

Dziminska, M., Mendoza-Poudereux, I., Pellegrini, G. and Rowland, J. (2021).

'Climate change and public perception. Citizens' proposals for better communication and involvement'. JCOM 20 (03), A09. https://doi.org/10.22323/2.20030209. 